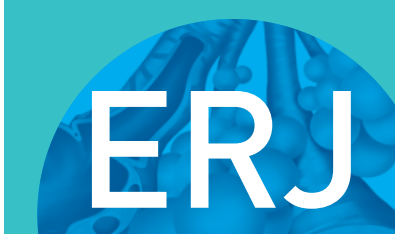

open research
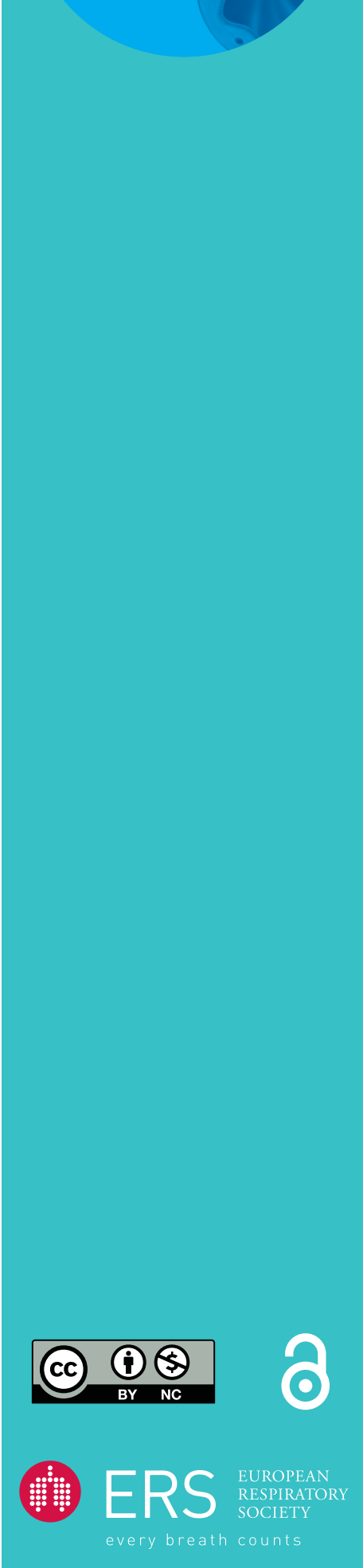

\section{Unilateral diaphragmatic paralysis: inspiratory muscles, breathlessness and exercise capacity}

\author{
Mayra Caleffi Pereira (10 ${ }^{1}$, Letícia Z. Cardenas ${ }^{1,2}$, Jeferson G. Ferreira ${ }^{1,2}$, \\ Vinícius C. Iamonti ${ }^{1}$, Pauliane Vieira Santana ${ }^{1,2}$, André Apanavicius ${ }^{1}$, \\ Pedro Caruso ${ }^{1,2}$, Angelo Fernandez ${ }^{3}$, Carlos R.R. de Carvalho ${ }^{1}$, \\ Daniel Langer (10) ${ }^{4}$ and André L.P. de Albuquerque ${ }^{1,5}$
}

\section{ABSTRACT}

Background: Patients with unilateral diaphragmatic paralysis (UDP) may present with dyspnoea without specific cause and limited ability to exercise. We aimed to investigate the diaphragm contraction mechanisms and nondiaphragmatic inspiratory muscle activation during exercise in patients with UDP, compared with healthy individuals.

Methods: Pulmonary function, as well as volitional and nonvolitional inspiratory muscle strength were evaluated in 35 patients and in 20 healthy subjects. Respiratory pressures and electromyography of scalene and sternocleidomastoid muscles were continuously recorded during incremental maximal cardiopulmonary exercise testing until symptom limitation. Dyspnoea was assessed at rest, every $2 \mathrm{~min}$ during exercise and at the end of exercise with a modified Borg scale.

Main results: Inspiratory muscle strength measurements were significantly lower for patients in comparison to controls (all $\mathrm{p}<0.05$ ). Patients achieved lower peak of exercise (lower oxygen consumption) compared to controls, with both gastric $\left(-9.8 \pm 4.6 \mathrm{cmH}_{2} \mathrm{O}\right.$ versus $\left.8.9 \pm 6.0 \mathrm{cmH}_{2} \mathrm{O}\right)$ and transdiaphragmatic $\left(6.5 \pm 5.5 \mathrm{cmH}_{2} \mathrm{O}\right.$ versus $\left.26.9 \pm 10.9 \mathrm{cmH}_{2} \mathrm{O}\right)$ pressures significantly lower, along with larger activation of

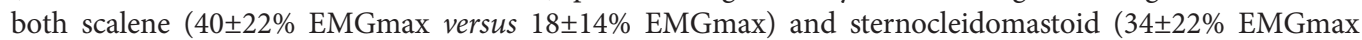
versus $14 \pm 8 \%$ EMGmax). In addition, the paralysis group presented significant differences in breathing pattern during exercise (lower tidal volume and higher respiratory rate) with more dyspnoea symptoms compared to the control group.

Conclusion: The paralysis group presented with exercise limitation accompanied by impairment in transdiaphragmatic pressure generation and larger accessory inspiratory muscles activation compared to controls, thereby contributing to a neuromechanical dissociation and increased dyspnoea perception.

@ERSpublications

The exercise capacity limitation in patients with unilateral diaphragmatic paralysis is characterised by an inefficient hemidiaphragm contraction. Consequently, there is a neuromechanical dissociation with an overload of inspiratory accessory muscles and higher breathlessness. https://bit.ly/2XxAR4K

Cite this article as: Caleffi Pereira M, Cardenas LZ, Ferreira JG, et al. Unilateral diaphragmatic paralysis: inspiratory muscles, breathlessness and exercise capacity. ERJ Open Res 2021; 7: 003572019 [https://doi.org/10.1183/23120541.00357-2019].

Received: 18 Dec 2019 | Accepted after revision: 30 May 2020

Copyright $\odot$ ERS 2021. This article is open access and distributed under the terms of the Creative Commons Attribution Non-Commercial Licence 4.0. 


\section{Introduction}

The diaphragm dysfunction is an underdiagnosed cause of dyspnoea. It is characterised by partial loss of the ability to generate pressure, which is considered diaphragm weakness, or complete loss of function, which is considered diaphragm paralysis. The main mechanism related to this condition is the phrenic nerve disfunction caused by situations such as trauma, surgery, chest tumours, myopathies, neuropathies and metabolic or inflammatory disorders [1]. The commitment involves either one or both hemidiaphragms. Differently from the bilateral involvement in which dyspnoea is intense even at rest, patients with unilateral diaphragmatic paralysis (UDP) are usually asymptomatic at rest, but may experience exertional dyspnoea, depending upon the severity of the paralysis and comorbid condition including obesity and intrinsic lung disease. Additionally, patients with UDP may experience dyspnoea in supine position and difficulty sleeping [2]. The lung function may present normal or slightly reduced vital capacity (VC). However, measurements of lung volumes in seated position are nonspecific, the change in VC measured from the seated to supine position is more consistent to evaluate diaphragm disfunction. The dysfunction can be confirmed by measuring the inspiratory force or more specifically the transdiaphragmatic pressure (Pdi), in association with image evaluation (usually by ultrasound) $[3,4]$.

It is known that the inspiratory muscle function is correlated with exercise capacity, and patients with UDP have decreased exercise tolerance $[5,6]$. However, the diaphragm contraction mechanism, the role of the nondiaphragmatic inspiratory muscles in exercise capacity and augmented dyspnoea in this population have not been thoroughly described. This is a highly relevant topic that included defining whether diaphragm dysfunction is the limiting factor of exercise impairment and higher dyspnoea, which is likely a good candidate for surgical correction and/or even ventilatory muscle training.

We hypothesised that the exercise limitation and the augmented exertional breathlessness in patients with UDP are justified by the noneffective force of involved hemidiaphragm in association to overloading the nondiaphragmatic inspiratory muscles. This study aimed to investigate the diaphragm and nondiaphragmatic inspiratory muscles activation with breathlessness during exercise in patients with UDP, compared with healthy individuals.

\section{Methods}

\section{Subjects}

This was a cross-sectional study involving 35 patients with UDP, who were consecutively recruited from a tertiary university hospital. All diagnoses were confirmed by the respiratory physician, using complementary imaging studies with chest computed tomography and chest radiography (elevated hemidiaphragm); the absence of diaphragm mobility was confirmed by ultrasound when the elevation of hemidiaphragm was not so marked (defined by the respiratory physician). Besides that, we included patients with $\mathrm{FVC}<80 \%$ of predicted, maximal inspiratory pressure $\left(P_{\operatorname{Imax}}\right)<80 \%$ of predicted, along with dyspnoea symptom, and body mass index between $20-30 \mathrm{~kg} / \mathrm{m}^{2}$. Patients with comorbidities that could develop exertional dyspnoea, including COPD, interstitial lung diseases, cardiac heart failure $(\mathrm{EF}<55 \%)$ and neuromuscular disorders were excluded. A control group composed of 20 healthy subjects, matched by sex and weight, with normal lung function $\left(\mathrm{FEV}_{1}>80 \%\right.$ of predicted and forced vital capacity (FVC) $>80 \%$ of predicted) who were physically inactive (exercise activity less than twice a week) was included.

\section{Study approval}

This study was approved by the local ethics committee (CapPesq) (protocol number: 0835/11) and all subjects provided written informed consent.

\section{Study protocol}

Dyspnoea assessment and respiratory function measurements, such as lung function tests and inspiratory muscle strength were performed at baseline. Metabolic, cardiovascular, and respiratory variables were

Affiliations: ${ }^{1}$ Pulmonary Division, Heart Institute (InCor), Hospital das Clínicas HCFMUSP, Faculdade de Medicina, Universidade de São Paulo, São Paulo, Brazil. ${ }^{2}$ Intensive Care Unit, AC Camargo Cancer Center, São Paulo, Brazil. ${ }^{3}$ Thoracic Surgery Division, InCor, Hospital das Clínicas HCFMUSP, Faculdade de Medicina, Universidade de São Paulo, São Paulo, Brazil. ${ }^{4}$ Faculty of Kinesiology and Rehabilitation Sciences, Dept of Rehabilitation Sciences, Research Group for Cardiovascular and Respiratory Rehabilitation, KU Leuven University of Leuven, and Respiratory Rehabilitation and Respiratory Division, University Hospital Leuven, Leuven, Belgium. ${ }^{5}$ Sírio-Libanês Teaching and Research Institute, São Paulo, Brazil.

Correspondence: André L.P. de Albuquerque, Pulmonary Division, InCor, Hospital das Clínicas da Faculdade de Medicina da Universidade de São Paulo, Av. Dr Enéas Carvalho Aguiar, n44, Cerqueira Cesar, São Paulo, 05403-900, Brazil. E-mail: alpalbuquerquedahotmail.com 
assessed during an incremental maximal cardiopulmonary exercise test with continuous measurement of oesophageal $\left(P_{\mathrm{oes}}\right)$, gastric $\left(P_{\mathrm{ga}}\right)$, transdiaphragmatic $\left(P_{\mathrm{di}}\right)$ pressures and surface electromyography $(\mathrm{EMG})$ of scalene and sternocleidomastoid muscles. All the measurements were completed during a single visit.

\section{Measurements at rest}

Dyspnoea assessment

All subjects were asked to identify their degree of dyspnoea, indicating the extent to which the breathlessness affects their mobility, according to the Medical Research Council Breathlessness Scale [7].

\section{Pulmonary function}

Forced expiratory volume in $1 \mathrm{~s}\left(\mathrm{FEV}_{1}\right), \mathrm{FVC}$, inspiratory capacity (IC), maximal voluntary ventilation (MVV), total lung capacity (TLC), carbon monoxide diffusing capacity $\left(D_{\mathrm{LCO}}\right)$ and carbon monoxide diffusing capacity by alveolar ventilation $\left(V_{\mathrm{A}}\right)$ coefficient $\left(D_{\mathrm{LCO}} / V_{\mathrm{A}}\right)$ were measured according to European Respiratory Society/American Thoracic Society guidelines [8-10]. The predicted values for lung function were derived from the Brazilian population [11-13]. Additional details on the methods for pulmonary function measurements are provided in the online data supplement.

\section{Inspiratory muscle function}

Maximal static inspiratory mouth $\left(P_{\text {Imax }}\right)$ and sniff nasal inspiratory (SNIP) pressures were measured using a digital manovacuometer. Oesophageal, gastric and transdiaphragmatic pressures were measured during a sniff manoeuvre (sniff $P_{\mathrm{oes}}$, sniff $P_{\mathrm{ga}}$ and sniff $P_{\mathrm{di}}$ respectively) and magnetic phrenic nerve stimulation (twitch $P_{\mathrm{oes}}$, twitch $P_{\mathrm{ga}}$ and twitch $P_{\mathrm{di}}$ respectively), using two air-filled balloon catheters positioned and calibrated according to the technique described elsewhere [14]. The reference values for $P_{\operatorname{Imax}}$ and SNIP were derived from the Brazilian population [15, 16]. Additional details on the methods for these inspiratory muscle function measurements are provided in the online data supplement.

\section{Measurements during exercise}

Exercise testing

All subjects underwent an incremental maximal cardiopulmonary exercise testing (CPET) on a cycle ergometer until exhaustion. During the test, respiratory and metabolic variables were recorded. The reference values for exercise testing were based on a sedentary adult Brazilian population [17]. The IC and the modified Borg Rating of Perceived Exertion Scale [18] were assessed at rest, every 2 min, and at the end of the exercise. Additional details on the methods for exercise testing are provided in the online data supplement.

\section{Inspiratory muscle function}

During the exercise, continuous recordings of oesophageal, gastric and transdiaphragmatic pressures, as described above, and surface electromyography (EMG) of scalene and sternocleidomastoid muscles were performed. Additional details on the methods for EMG signal acquisition are provided in the online data supplement.

All measurements were performed breath by breath, and mean values were drawn from the last $20 \mathrm{~s}$ of each stage (submaximal) and peak. AqDados 7.0 software (Lynx technology, Brazil) was used for data acquisition and the AqAnalysis 7.0 (Lynx technology, Brazil) for data analysis.

\section{Statistical analysis}

Statistical analysis was performed using SPSS 21.0 (IBM SPSS Statistics, USA) and SigmaPlot 12.3 (Systat Software Inc., USA). Normality of distributions was tested using the Shapiro-Wilk test. Data are expressed as mean $\pm \mathrm{SD}$, mean \pm SEM for the graph presentations or median (25th-75th percentile) as appropriate. An independent $t$-test was performed to compare both paralysis and control groups at baseline and at exercise peak. A two-way repeated measures ANOVA was performed to observe the relationship between variables and both groups at iso-work rate or at similar ventilation. The significance level was set to $5 \%(\mathrm{p}<0.05)$.

\section{Results}

\section{Subjects}

Among the patients, 13 presented with right and 22 with left paralysis. Idiopathic and trauma were the most common causes of diaphragmatic dysfunction (29\% and $37 \%$, respectively). General characteristics of patients with unilateral diaphragm paralysis and healthy control subjects are presented in table 1 . 


\begin{tabular}{|c|c|c|c|}
\hline & Paralysis group & Control group & p-value \\
\hline Male & $17(49)$ & $10(50)$ & 0.92 \\
\hline Age years & $55.8 \pm 9.9(32-77)$ & $49.8 \pm 6.4(40-58)$ & 0.03 \\
\hline Weight kg & $75.5 \pm 11.8$ (48-99) & $78.7 \pm 9.8$ (65-105) & 0.32 \\
\hline Height m & $1.63 \pm 0.1(1.5-1.9)$ & $1.68 \pm 0.1(1.5-1.9)$ & 0.07 \\
\hline BMI $\mathrm{kg} \cdot \mathrm{m}^{-2}$ & $28.4 \pm 3.4(22.2-35.6)$ & $27.9 \pm 2.1(22.5-29.8)$ & 0.49 \\
\hline Left paralysis & $22(63)$ & - & - \\
\hline \multicolumn{4}{|l|}{ Cause of paralysis } \\
\hline Idiopathic & $10(29)$ & - & - \\
\hline Trauma & 13 (37) & - & - \\
\hline After cardiac surgery & 8 (23) & - & - \\
\hline After thoracic surgery & $4(11)$ & - & - \\
\hline
\end{tabular}

\section{Measurements at rest}

Pulmonary function dyspnoea

The paralysis group presented with lower $\mathrm{FEV}_{1}$ and $\mathrm{FVC}$ compared with controls. When performed with the patient in the supine position, a reduction by $12 \%$ was observed in the FVC. Paralysis patients had reduced TLC and $D_{\mathrm{LCO}}$, with normal $D_{\mathrm{LCO}} / V_{\mathrm{A}}$. Scores for moderate dyspnoea were reported by $66 \%(40 \%$ for MRC 2 and 26\% for MRC 3) of paralysis patients with one reporting severe dyspnoea (MRC 4) (table 2).

\section{Inspiratory muscle function}

The paralysis group had global inspiratory weakness evidenced by $P_{\text {Imax }}$, SNIP and sniff $P_{\text {oes }}$ significantly decreased compared with controls (table 3). A paradoxical response in $P_{\text {ga }}$ (Fig. 1) was observed during the sniff manoeuvre in $86 \%$ of paralysis patients, resulting in lower sniff $P_{\mathrm{di}}$ values compared with that in controls. In addition, the transdiaphragmatic pressure in response to the magnetic phrenic nerve stimulation (twitch $P_{\mathrm{di}}$ ) measurement evidenced diaphragm weakness at affected hemidiaphragm,

TABLE 2 Lung function and dyspnoea assessment of patients with unilateral diaphragmatic paralysis and control group at rest

\begin{tabular}{|c|c|c|c|}
\hline & Paralysis group & Control group & p-value \\
\hline \multicolumn{4}{|l|}{ Lung function } \\
\hline FEV 1 sitting $L(\%$ pred $)$ & $1.8 \pm 0.6(59 \pm 13)$ & $2.9 \pm 0.5(92 \pm 9)$ & $<0.001$ \\
\hline FVC sitting L (\% pred) & $2.3 \pm 0.8(62 \pm 13)$ & $3.5 \pm 0.7(92 \pm 8)$ & $<0.001$ \\
\hline $\mathrm{FEV}_{1} / \mathrm{FVC} \%$ & $80 \pm 11$ & $82 \pm 5$ & 0.24 \\
\hline FVC supine L (\% pred) & $2.0 \pm 0.7(56 \pm 13)$ & - & - \\
\hline$\Delta \mathrm{FVC}$ sitting versus supine $\%$ & $-12 \pm 8$ & - & - \\
\hline IC L (\% pred) & $1.7 \pm 0.5(64 \pm 13)$ & $2.7 \pm 0.5(87 \pm 14)$ & $<0.001$ \\
\hline MVV L (\% pred) & $82.1 \pm 22.8(65 \pm 13)$ & $120.0 \pm 30.9(85 \pm 20)$ & $<0.001$ \\
\hline TLC L (\% pred) & $4.2 \pm 0.9(73 \pm 21)$ & - & - \\
\hline$D_{\text {Lco }}(\%$ pred $)$ & $20.1 \pm 8.3(66 \pm 38)$ & - & - \\
\hline$D_{\mathrm{L}} / V_{\mathrm{A}}(\%$ pred $)$ & $5.28 \pm 1.50(107 \pm 35)$ & - & - \\
\hline \multicolumn{4}{|l|}{ MRC } \\
\hline 1 & $11(31)$ & $20(100)$ & $<0.001$ \\
\hline 2 & $14(40)$ & $0(0)$ & - \\
\hline 3 & $9(26)$ & $0(0)$ & - \\
\hline 4 & $1(3)$ & $0(0)$ & - \\
\hline 5 & $0(0)$ & $0(0)$ & - \\
\hline \multicolumn{4}{|c|}{$\begin{array}{l}\text { Data are presented as mean } \pm \text { SD or } n(\%) \text {, unless otherwise stated. } F E V_{1} \text { : forced expiratory volume in } 1 \mathrm{~s} ; \% \\
\text { pred: \% predicted; FVC: forced vital capacity, IC: inspiratory capacity; MVV: maximal voluntary ventilation; } \\
\text { TLC: total lung capacity, } D_{\mathrm{LCO}} \text { : carbon monoxide diffusing capacity; } D_{\mathrm{L}} / V_{\mathrm{A}} \text { : carbon monoxide diffusing } \\
\text { capacity by alveolar ventilation coefficient; MRC: Medical Research Council Breathlessness Scale. }\end{array}$} \\
\hline
\end{tabular}




\begin{tabular}{|c|c|c|c|}
\hline & $\begin{array}{l}\text { Paralysis } \\
\text { group }\end{array}$ & Control group & p-value \\
\hline \multicolumn{4}{|l|}{ Volitional inspiratory muscle strength } \\
\hline$P_{\operatorname{Imax}} \mathrm{CmH}_{2} \mathrm{O}(\%$ pred $)$ & $-67 \pm 25(55 \pm 23)$ & $-103 \pm 30(100 \pm 21)$ & $<0.001$ \\
\hline SNIP $\mathrm{cmH}_{2} \mathrm{O}$ (\% pred) & $57 \pm 18(58 \pm 15)$ & $96 \pm 20(89 \pm 28)$ & $<0.001$ \\
\hline Sniff $P_{\text {oes }} \mathrm{cmH}_{2} \mathrm{O}$ & $-44 \pm 13$ & $-66 \pm 26$ & 0.001 \\
\hline Sniff $P_{\mathrm{ga}} \mathrm{CmH}_{2} \mathrm{O}$ & $-10 \pm 9$ & $36 \pm 14$ & $<0.001$ \\
\hline Sniff $P_{\mathrm{di}} \mathrm{cmH}_{2} \mathrm{O}$ & $34 \pm 17$ & $102 \pm 26$ & $<0.001$ \\
\hline \multicolumn{4}{|l|}{ Nonvolitional inspiratory muscle strength } \\
\hline Twitch $P_{\text {di }}$ (bilateral) $\mathrm{cmH}_{2} \mathrm{O}$ & $5.3 \pm 2.7$ & $15.3 \pm 5.7$ & $<0.001$ \\
\hline 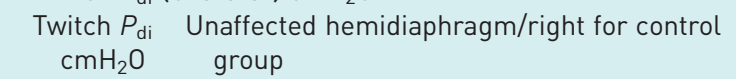 & $3.5 \pm 1.3$ & $7.4 \pm 2.7$ & $<0.001$ \\
\hline $\begin{array}{cc}\text { Twitch } P_{\mathrm{di}} & \text { Affected hemidiaphragm/left for control } \\
\mathrm{cmH}_{2} \mathrm{O} & \text { group }\end{array}$ & $2.5 \pm 1.1$ & $8.9 \pm 3.4$ & $<0.001$ \\
\hline
\end{tabular}

Data are presented as mean \pm SD, unless otherwise stated. $P_{\text {Imax }}$ : maximal static inspiratory pressure; SNIP: sniff nasal inspiratory pressure; Sniff $P_{\text {oes }}$ : oesophageal pressure during sniff manoeuvre; Sniff $P_{\text {ga: }}$ gastric pressure during sniff manoeuvre; Sniff $P_{\text {di }}$ : transdiaphragmatic pressure during sniff manoeuvre; Twitch $P_{\text {di }}$ : transdiaphragmatic pressure during phrenic nerve magnetic stimulation.

unaffected hemidiaphragm and bilateral stimulation in paralysis patients (table 3) compared with controls. There was no difference in the respiratory strength related to the paralysed side.

\section{Measurements during exercise}

\section{Exercise testing}

The paralysis group achieved lower peak work rate along with reduced oxygen consumption $\left(V^{\prime}{ }_{\mathrm{O}_{2}}\right)$ than did the control group, with $85 \%$ of maximal heart rate (table 4$)$. The tidal volume $\left(V_{\mathrm{T}}\right)$, ventilation $\left(V_{\mathrm{E}}\right)$
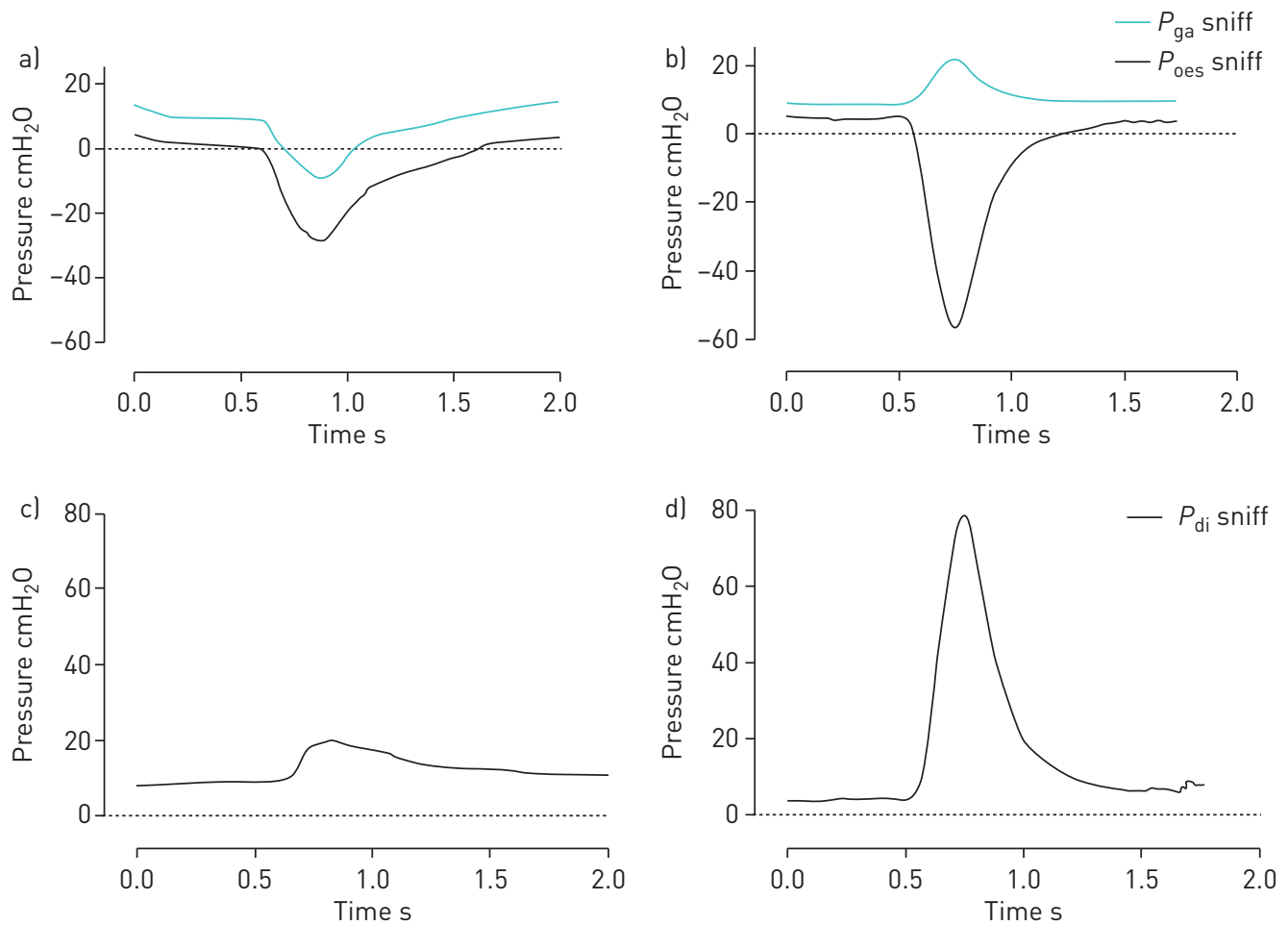

FIGURE 1 Illustration of oesophageal $\left(P_{\text {oes }}\right)$, gastric $\left(P_{\mathrm{ga}}\right)$, transdiaphragmatic $\left(P_{\mathrm{di}}\right)$ pressure curves during sniff manoeuvre in a patient with unilateral diaphragm paralysis $(a, b)$ and in a healthy control subject $(c, d)$. 


\begin{tabular}{|c|c|c|c|}
\hline & Paralysis group & Control group & p-value \\
\hline \multicolumn{4}{|l|}{ CPET performance } \\
\hline Work rate W (\% pred) & $83.9 \pm 38.5(54 \pm 26)$ & $152.3 \pm 55.2(90 \pm 41)$ & $<0.001$ \\
\hline$V^{\prime} \mathrm{O}_{2} \mathrm{~mL} \cdot \mathrm{kg}^{-1} \cdot \mathrm{min}^{-1}(\%$ pred $)$ & $18.7 \pm 5.5(90.2 \pm 20.1)$ & $25.3 \pm 9.5(106.7 \pm 21.8)$ & 0.01 \\
\hline RER & $0.99 \pm 0.13$ & $1.09 \pm 0.09$ & 0.01 \\
\hline \multicolumn{4}{|l|}{ Ventilation and gas exchange } \\
\hline$V_{\mathrm{T}} \mathrm{L}$ & $1.3 \pm 0.5$ & $1.9 \pm 0.4$ & $<0.001$ \\
\hline$V_{\mathrm{T}} / \mathrm{IC} \%$ & $72 \pm 11$ & $72 \pm 8$ & 0.93 \\
\hline$V_{E} L \cdot \min ^{-1}$ & $51.5 \pm 16.9$ & $74.7 \pm 23.7$ & 0.001 \\
\hline RR bpm & $42 \pm 9$ & $39 \pm 9$ & 0.24 \\
\hline$V_{E} / M V V$ & $0.6 \pm 0.3$ & $0.6 \pm 0.2$ & 0.44 \\
\hline IC L & $1.6 \pm 0.4$ & $2.8 \pm 0.5$ & $<0.001$ \\
\hline$\Delta I C$ (peak-rest) L & $0.0 \pm 0.2$ & $0.6 \pm 1$ & 0.03 \\
\hline$V_{\mathrm{E}} / V_{\mathrm{CO}_{2}}$ & $36 \pm 5$ & $35 \pm 3$ & 0.86 \\
\hline $\mathrm{S}_{\mathrm{pO}_{2}} \%$ & $93 \pm 3$ & $95 \pm 1$ & 0.06 \\
\hline \multicolumn{4}{|l|}{ Cardiovascular } \\
\hline HR bpm (\% pred) & $138 \pm 22(85 \pm 12)$ & $157 \pm 19(93 \pm 10)$ & 0.003 \\
\hline $\mathrm{O}_{2}$ pulse $\mathrm{mL} \cdot \mathrm{bpm}^{-1}(\%$ pred $)$ & $14 \pm 3(82 \pm 21)$ & $15 \pm 5(89 \pm 28)$ & 0.15 \\
\hline \multicolumn{4}{|l|}{ Symptoms } \\
\hline Borg modified (dyspnoea) & $9(7-10)$ & $5(3.25-9)$ & 0.001 \\
\hline Borg modified (legs effort) & $9(7-10)$ & $7(5-8.75)$ & 0.02 \\
\hline \multicolumn{4}{|c|}{ 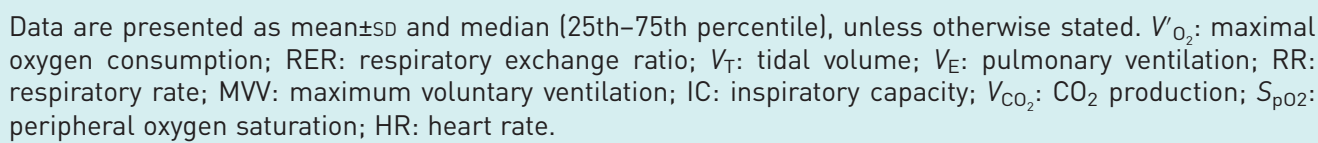 } \\
\hline
\end{tabular}

and the increment of IC ( $\Delta$ IC) were decreased. In addition, the symptoms of dyspnoea and leg effort were higher in the paralysis group compared with the controls at peak exercise (table 4).

Both groups had similar $V_{\mathrm{O}_{2}}^{\prime}, V_{\mathrm{E}}$ and $V_{\mathrm{T}}$ at most iso-work rate comparisons with a significant difference between them at the peak of exercise (figure $2 \mathrm{a}-\mathrm{c}$ ). However, the paralysis group had a higher respiratory rate (RR) at submaximal exercise intensities (figure $2 \mathrm{~d}$ ) and reported higher leg effort perception scores with higher dyspnoea even at very light exercise compared with the control group (figure 2e,f).

\section{Inspiratory muscle function}

Throughout incremental exercise, at iso-work rate, the paralysis group generated higher $P_{\text {oes }}$ along with higher scalene (EMGsca/sca, max) and sternocleidomastoid (EMGscm/scm max) activation compared with the control group (figure 3a,d,e). In contrast with healthy individuals who increased the $P_{\mathrm{ga}}$ and $P_{\mathrm{di}}$ during exercise, in the paralysis group $P_{\mathrm{ga}}$ was progressively negative, and, as a consequence, the $P_{\mathrm{di}} \operatorname{did}$ not increase through exercise (figure 3b,c). At peak of exercise, lower respiratory pressures were found in the paralysis group, compared to controls, with $-9.8 \pm 4.6 \mathrm{cmH}_{2} \mathrm{O}$ versus $8.9 \pm 6.0 \mathrm{cmH}_{2} \mathrm{O}$ for gastric pressure and $6.5 \pm 5.5 \mathrm{cmH}_{2} \mathrm{O}$ versus $26.9 \pm 10.9 \mathrm{cmH}_{2} \mathrm{O}$ for transdiaphragmatic pressure. In addition, paralysis group

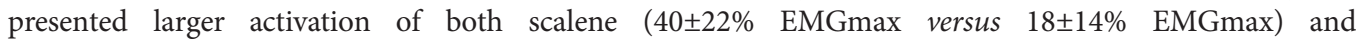
sternocleidomastoid ( $34 \pm 22 \%$ EMGmax versus $14 \pm 8 \%$ EMG max) compared to control group.

Furthermore, correcting for similar ventilation, a lower $P_{\mathrm{di}}$ was observed in the paralysis group with higher $P_{\text {oes }} / P_{\text {oes }}$, max generation, EMGsca/EMGsca, max activation, and dyspnoea perception compared with controls (figure 4).

\section{Discussion}

Our main finding was the impaired mechanism of diaphragm contraction in UDP patients, characterised by the paradoxical response of the gastric pressure (negative values), which worsens during effort and is associated with relevant clinical implications, such as higher recruitment of inspiratory accessory muscles and higher dyspnoea, contributing to the reduced exercise capacity, compared to healthy subjects. 
- Paralysis group -o- Control group
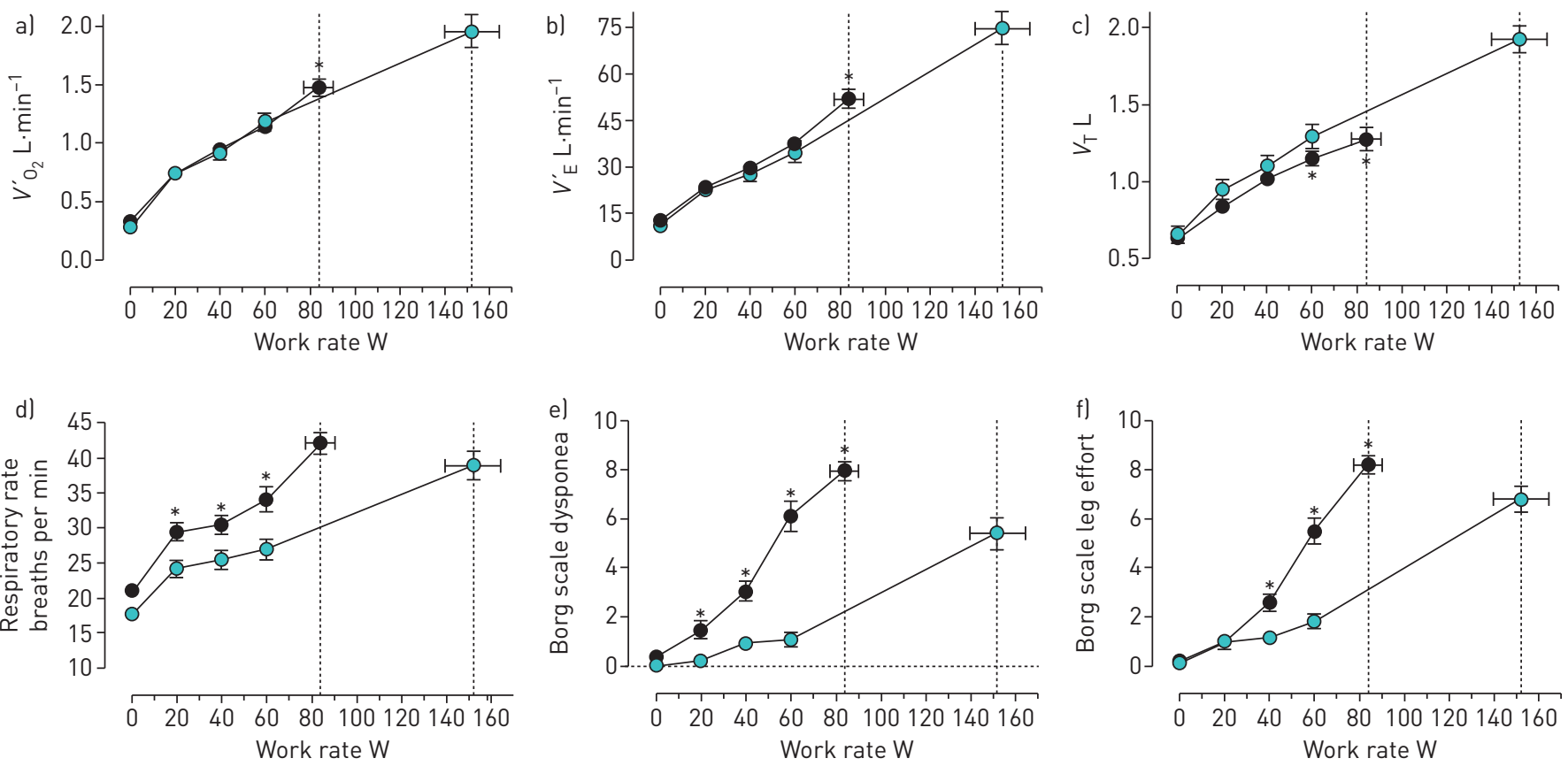

FIGURE 2 Metabolic and respiratory variables during incremental cycling exercise in patients with unilateral diaphragmatic paralysis (paralysis group) and healthy control group (CG). a) Peak oxygen uptake $\left(V^{\prime}{ }_{O}\right)$, b) Ventilation $\left(V_{E}\right)$, c) Tidal volume $\left(V_{T}\right)$, d) respiratory rate $(R R)$, e) Borg score for dyspnoea and f) Borg score for leg effort. Dotted lines represent the peak of exercise for each group. Values represent mean \pm SEM. ${ }^{*} p<0.05$ for paralysis group versus CG at iso-work rate or peak of exercise.

Paralysis group -o- Control group
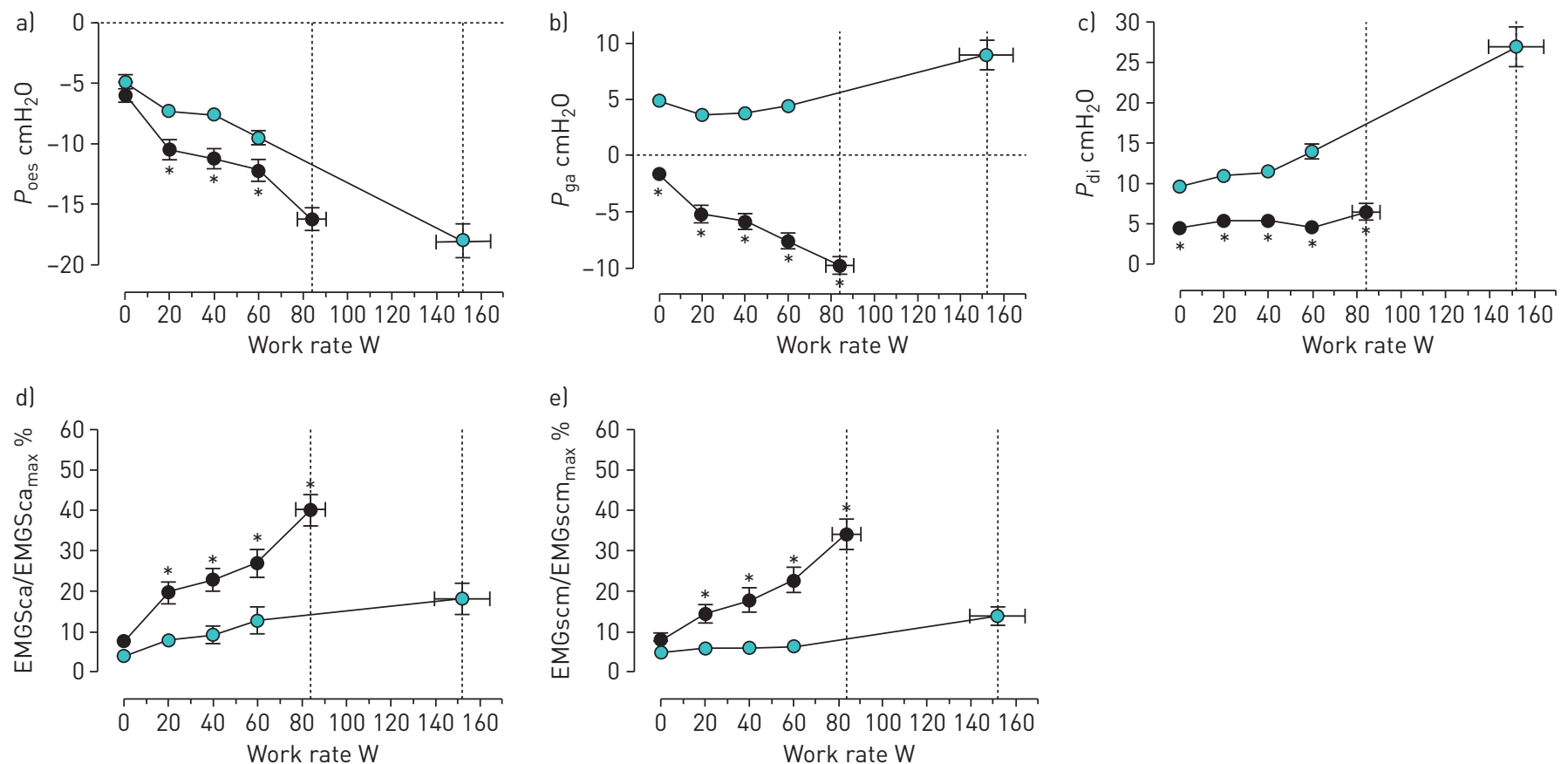

FIGURE 3 Inspiratory oesophageal $\left(P_{\text {oes }}\right)$, gastric $\left(P_{\text {ga }}\right)$, transdiaphragmatic $\left(P_{\mathrm{di}}\right)$ pressures $(a-c)$ and percentage of maximal scalene $(E M G s c a /$ EMGsca, max) and sternocleidomastoid (EMGscm/ EMGscm, max) muscle activation (d, e) during incremental cycling exercise in patients with unilateral diaphragmatic paralysis (paralysis group) and healthy control group (CG). Dotted lines represent the peak of exercise for each group. Values represent mean \pm SEM. ${ }^{*} p<0.05$ for paralysis group versus control group at iso-work rate or peak of exercise. 
Paralysis group $\square$ Control group
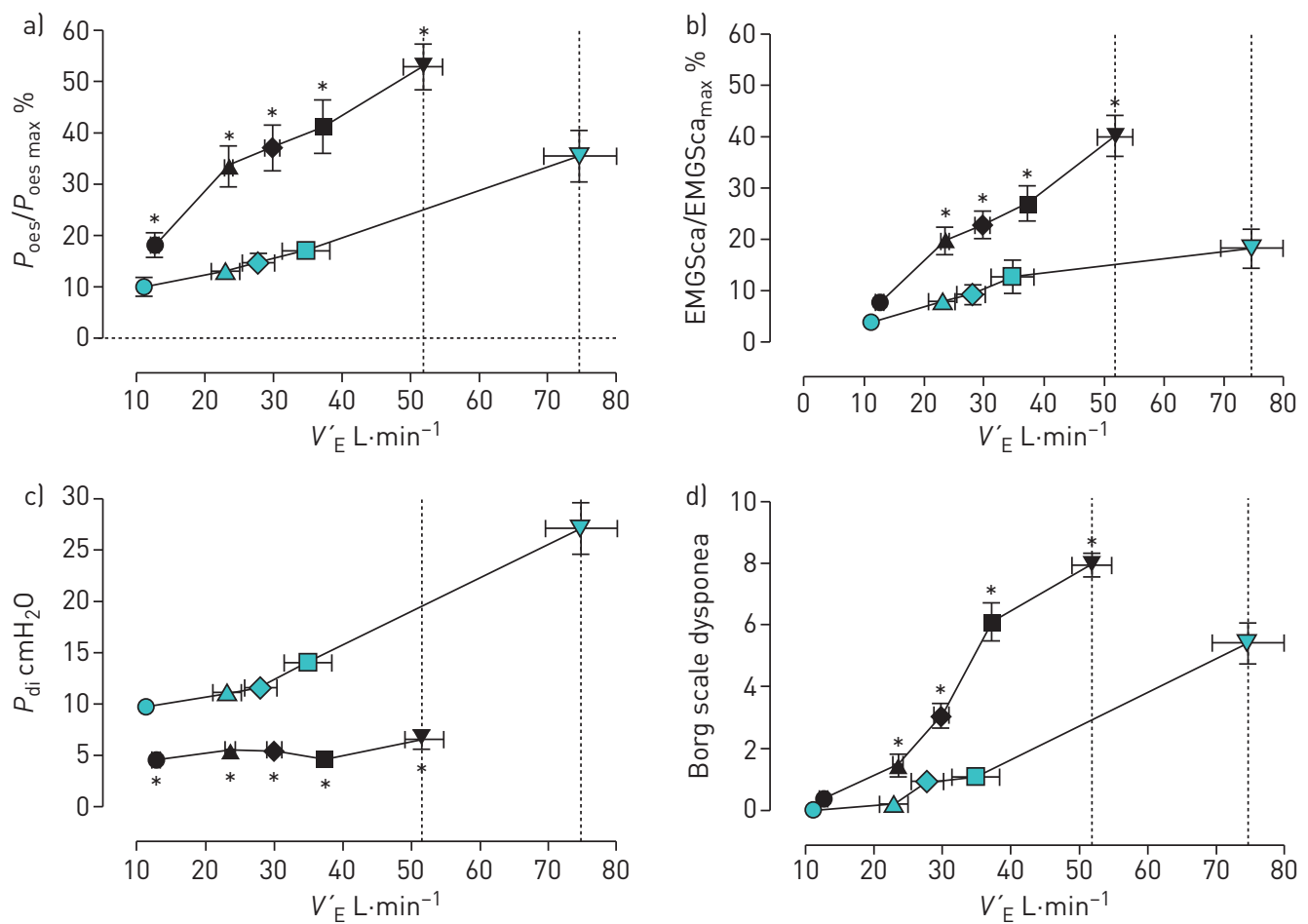

FIGURE 4 Percentage of maximal oesophageal pressure generation $\left(P_{\text {oes }} / P_{\text {oes }}\right.$ max $)(a)$; percentage of maximal scalene activation (EMGsca/ EMGsca, max) (b); transdiaphragmatic pressure $\left(P_{\mathrm{di}}\right)(\mathrm{c})$; and Borg score for dyspnoea (d) during incremental cycling exercise in patients with unilateral diaphragmatic paralysis (paralysis groupl and healthy control group (CG) at similar ventilation. $V_{E}$ : ventilation. Dotted lines represent the peak of exercise for each group. Values represent mean \pm SEM. ${ }^{*}: p<0.05$ for paralysis group versus control group at similar $V_{E}$ or peak of exercise (matching symbols).

\section{Measurements at rest}

\section{Pulmonary function}

After clinical and image evaluation, diaphragmatic dysfunction in the paralysis group was confirmed by a reduction of $35 \%$ in the FVC, with a further decrease of $12 \%$ when the FVC manoeuvre was performed with the patient in the supine position (Table 2). It is well established that unilateral diaphragmatic involvement is related to a mild decrease (10 to 30\%) in VC and a further decrease of $10-20 \%$ with the patient in the supine position $[1,19,20]$. Koo et al. [21] described a change in VC performed in the supine position of $5.3 \%$ for normal diaphragm function, $13.8 \%$ for unilateral paralysis and $37 \%$ for bilateral paralysis.

\section{Inspiratory muscle function}

Our patients had significant inspiratory muscle weakness compared to control group, with 55\% and 58\% of predicted for $P_{\text {Imax }}$ and SNIP, respectively (table 3). The sniff manoeuvre with pressure measurement also evidenced significant global inspiratory muscle weakness compared with the controls (table 3). Although there are no normal values described for the sniff manoeuvre, the range can vary between 52 to $150 \mathrm{cmH}_{2} \mathrm{O}$ for sniff $P_{\text {oes }}$ and 82 to $204 \mathrm{cmH}_{2} \mathrm{O}$ for sniff $P_{\mathrm{di}}$ in healthy subjects $[4,22]$ and a variation has been described between subjects in the oesophageal and gastric pressures contribution to the sniff $P_{\mathrm{di}}$ [22]. Of note, the low sniff $P_{\mathrm{di}}$ in the paralysis group is probably related to the paradoxical response (negative values) in the $P_{\mathrm{ga}}$ during the manoeuvre, which reflects the impaired diaphragm contraction mechanism (figure 1; table 3). Recently, a paradoxical response of the $P_{\mathrm{ga}}$ during the sniff manoeuvre was described in a man with unilateral diaphragmatic dysfunction [23], but it is not described in the healthy control subjects. Mills et al. [24] suggest that the fall in $P_{\text {ga }}$ during the sniff manoeuvre is due to the diaphragm being pushed up into the chest, reducing abdominal pressure.

The twitch $P_{\mathrm{di}}$ measurement evidenced substantial diaphragm weakness in the paralysis group compared with the control group (table 3). Although normal values for twitch $P_{\mathrm{di}}$ in adults are lacking, the literature shows that a twitch $P_{\text {di }}$ of $<15 \mathrm{cmH}_{2} \mathrm{O}$ [4] or $<20 \mathrm{cmH}_{2} \mathrm{O}$ [2], and a unilateral twitch $P_{\text {di }}$ of $<10 \mathrm{cmH}_{2} \mathrm{O}$ [2] 
are indicative of diaphragmatic weakness. However, some variability must be considered even in healthy individuals, in which involves also technical aspects like pressure sensors and properties of tube [25]. Our results showed a unilateral twitch $P_{\mathrm{di}}$ of $2.5 \pm 1.1 \mathrm{cmH}_{2} \mathrm{O}$ (affected hemidiaphragm) in the paralysis group, in comparison to the control group, which agree with those described by HART et al. [6], who consider a right and/or left twitch $P_{\mathrm{di}}<3.5 \mathrm{cmH}_{2} \mathrm{O}$ as indicative of UDP. In addition, a previous study [14] described this important reduction twitch $P_{\mathrm{di}}$ in patients with UDP, with impairment of the force generation even of the preserved contralateral hemidiaphragm.

Like the $P_{\text {Imax }}$ and SNIP measurements, the sniff manoeuvre is a global measurement of the strength of the inspiratory muscle, that is, combined measures of diaphragmatic and nondiaphragmatic inspiratory muscle strength. On the other hand, the twitch $P_{\mathrm{di}}$ is useful to assess the diaphragm function specifically. However, it is an invasive technique and cause some patient discomfort. The ultrasound is a useful tool to evaluate the diaphragm function, since it is less invasive, simple and allows direct evaluation [2, 4]. In patients with UDP, the ultrasound is an important technique to assess the diaphragm mobility and thickness, as described previously [14].

\section{Measurements during exercise}

Exercise testing

The paralysis group had similar $V_{\mathrm{O}_{2}}^{\prime}$ and $V_{\mathrm{E}}$ compared with the controls at iso-work rate. However, they had reduced exercise capacity (lower peak work rate and $V_{\mathrm{O}_{2}}^{\prime}$ ) with a significant decrease in $V_{\mathrm{E}}$ and $V_{\mathrm{T}}$ at peak exercise. Interestingly, patients had increased RR and dyspnoea in very early exercise progression (figure 2). According to Bonnevie et al. [5], these patients have exercise limited by a pathological ventilatory pattern (low Vt and excessive RR). HART et al. [6] affirm that the exercise limitation is primarily associated with the reduced peak minute ventilation. However, in both studies the sample size is small and there was not any measurement of diaphragm or inspiratory accessory muscles, besides dyspnoea during exercise.

\section{Inspiratory muscle function}

Looking at diaphragm function and its mechanism of contraction during exercise, a higher $P_{\text {oes }}$ generation along with a paradoxical response in the $P_{\text {ga }}$ generation was observed, resulting in a very low $P_{\mathrm{di}}$ compared with that in the control group (figure $3 \mathrm{a}-\mathrm{c}$ ). Of note, the pathological contraction pattern characterised by the negative values of $P_{\mathrm{ga}}$ is present not only at rest but worsens with increasing work rate. It is probably the result of the diaphragm being suctioned into the chest (paradoxical movement during inspiration), as described during the sniff manoeuvre [24]. HART et al. [6] had already described this pattern at rest and its correlation with a worse exercise performance and reduced ventilation. We observed this paradoxical movement of the $P_{\text {ga }}$ at rest in $75 \%$ of the patients, with increase to $94 \%$ at $20 \mathrm{w}$ and to $100 \%$ at other loads and peak of the exercise.

At iso-work rate, the paralysis group had a greater percentage of activation of scalene (EMGsca/EMGsca, max) and sternocleidomastoid (EMGscm/EMGscm, max) than the controls had. At peak exercise, they reached twice the percentage of the controls (figure 3d,e). This result indicates that, at submaximal exercise, paralysis group probably maintained similar ventilatory conditions to that in the control group at the expense of the scalene and sternocleidomastoid activation. This result is in line with the statement that in face of the impaired diaphragm contraction, the inspiratory function is supposed to be partially compensated by other inspiratory muscles than the diaphragm [26]. In addition, the high activation of these muscles explains the higher $P_{\text {oes }}$ generation compared with controls (figure 3a) because the $P_{\text {oes }}$ measured during hyperpnoea condition is the result not only of diaphragm contraction but also of the nondiaphragmatic inspiratory muscles. This recruitment certainly results in higher dyspnoea sensation during exercise, even at mild intensities.

Briefly, the paralysis group present an increased inspiratory muscle effort combined with reduced tidal volume and increased RR at a given work rate or ventilation compared to the controls. It may reflect a mismatch between the respiratory drive and the mechanical responses (neuromechanical dissociation), probably resulting in increased dyspnoea [27]. Despite it is a mechanism of better adaptation to achieve a higher ventilation, the ultimate consequence is an overload of inspiratory accessory muscles and higher breathlessness.

Although the static respiratory muscle function is well described in patients with diaphragmatic dysfunction $[2,3,14,19,20,24,28]$, only two studies $[5,6]$ have described the influence of inspiratory muscle function on the exercise capacity in these patients. However, none of them applied the respiratory muscle function measurements during the exercise. This is the first study that shows a more comprehensive and dynamic evaluation of all inspiratory muscles and symptom-implication over the exercise. Our study measured the respiratory muscle function continuously throughout the exercise, with 
important results of over recruitment of the respiratory muscles and altered respiratory pressures responses in these patients compared to healthy subjects. Despite the statistical difference in the age between the groups, the average values (55.8 \pm 9.9 years for paralysis group and $49.8 \pm 6.4$ years for control group) are clinically very similar.

\section{Limitations}

Some limitations are present in this study. First, we based the impaired diaphragm contraction on the respiratory pressure responses. The diaphragm EMG measurements could provide us with additional information about diaphragm activation during exercise. Second, we studied the mechanisms of pressure generation and muscle activation only during inspiration. Results during expiration, such as abdominal activation or gastric pressure generation, could improve the findings. Third, we used unpotentiated twitch pressures instead of potentiated, which might be more sensitive. Fourth, we did not assess the reason for stopping the exercise, which could bring more detailed information about symptom limitation. Finally, the ultrasound could be a useful adjacent tool to identify the paradoxical diaphragm movement, but this measurement would be difficult to perform during the exercise.

\section{Conclusion}

In conclusion, patients with UDP had the pathological mechanism of diaphragm contraction (paradoxical Pga) that worsens during effort. This happens along with a neuromechanical dissociation, illustrated by the over recruitment of the nondiaphragmatic inspiratory muscles and lower tidal volume with higher RR, reducing the exercise performance and contributing to the higher dyspnoea.

This study carries an important clinical relevance since it reinforces the important role of the nondiaphragmatic inspiratory muscles in the exercise performance. Inspiratory muscle training has been described as an alternative to improve inspiratory muscle function in patients with unilateral diaphragm paralysis [23, 29-31], which likely has a positive impact on inspiratory accessory muscles. Nevertheless, studies are needed to further establish its benefits on exercise capacity in this population.

Acknowledgements: The authors thank all participating investigators of the Respiratory Muscles Group (Heart Institute - Incor) from the Hospital das Clínicas da Faculdade de Medicina da Universidade de São Paulo for their contribution to the collected data, and Ann Conti Morcos (medical writer/editor) for her contribution to language editing.

Author contributions: M. Caleffi Pereira, A.L.P. de Albuquerque, P. Caruso, C.R.R. de Carvalho and A. Fernandez contributed to the study conception and design. M. Caleffi Pereira, A.L.P. de Albuquerque, L.Z. Cardenas, J.G. Ferreira, V.C. Iamonti, P.V. Santana and A. Apanavicius contributed to data acquisition. M. Caleffi Pereira contributed to data analysis. M. Caleffi Pereira, D. Langer and A.L.P. de Albuquerque contributed to manuscript drafting. All authors contributed to the final manuscript approval.

Conflict of interest: None declared.

Support statement: This study was supported by São Paulo Research Foundation (Fapesp) (protocol number: 2011/ 20979-6) and Mayra Callefi-Pereira receives a PhD bursary from Conselho Nacional de Desenvolvimento Científico e Tecnológico (process number 142298/2016-6). Funding information for this article has been deposited with the Crossref Funder Registry.

\section{References}

McCool FD, Tzelepis GE. Dysfunction of the diaphragm. N Engl J Med 2012; 366: 932-942.

McCool FD, Manzoor K, Minami T. Disorders of the diaphragm. Clin Chest Med 2018; 39: 345-360.

Laveneziana P, Nierat MC, LoMauro A, et al. A case of unexplained dyspnoea: when lung function testing matters! Breathe 2018; 14: 325-332.

4 Laveneziana P, Albuquerque A, Aliverti A, et al. ERS statement on respiratory muscle testing at rest and during exercise. Eur Respir J 2019; 53: 1801214

5 Bonnevie T, Gravier FE, Ducrocq A, et al. Exercise testing in patients with diaphragm paresis. Respir Physiol Neurobiol 2018; 248: 31-35.

6 Hart N, Nickol AH, Cramer D, et al. Effect of severe isolated unilateral and bilateral diaphragm weakness on exercise performance. Am J Respir Crit Care Med 2002; 165: 1265-1270.

$7 \quad$ Mahler DA, Wells CK. Evaluation of clinical methods for rating dyspnea. Chest 1988; 93: 580-586.

8 Macintyre N, Crapo RO, Viegi G, et al. Standardisation of the single-breath determination of carbon monoxide uptake in the lung. Eur Respir J 2005; 26: 720-735.

9 Miller MR, Hankinson J, Brusasco V, et al. Standardisation of spirometry. Eur Respir J 2005; 26: 319-338.

10 Wanger J, Clausen JL, Coates A, et al. Standardisation of the measurement of lung volumes. Eur Respir J 2005; 26 : 511-522.

11 Neder JA, Andreoni S, Castelo-Filho A, et al. Reference values for lung function tests. I. Static volumes. Braz J Med Biol Res 1999; 32: 703-717.

12 Neder JA, Andreoni S, Peres C, et al. Reference values for lung function tests. III. Carbon monoxide diffusing capacity (transfer factor). Braz J Med Biol Res 1999; 32: 729-737.

13 Pereira CA, Sato T, Rodrigues SC. New reference values for forced spirometry in white adults in Brazil. $J$ Bras Pneumol 2007; 33: 397-406. 
14 Caleffi-Pereira M, Pletsch-Assuncao R, Cardenas LZ, et al. Unilateral diaphragm paralysis: a dysfunction restricted not just to one hemidiaphragm. BMC Pulm Med 2018; 18: 126.

15 Araujo PR, Resqueti VR, Nascimento Junior J, et al. Reference values for sniff nasal inspiratory pressure in healthy subjects in Brazil: a multicenter study. J Bras Pneumol 2012; 38: 700-707.

16 Neder JA, Andreoni S, Lerario MC, et al. Reference values for lung function tests. II. Maximal respiratory pressures and voluntary ventilation. Braz J Med Biol Res 1999; 32: 719-727.

17 Neder JA NL. Teste de exercício cardiopulmonar. J Pneumol 2002; 28: S166-S206.

18 Borg GA. Psychophysical bases of perceived exertion. Med Sci Sports Exerc 1982; 14: 377-381.

19 Laroche CM, Mier AK, Moxham J, et al. Diaphragm strength in patients with recent hemidiaphragm paralysis. Thorax 1988; 43: 170-174.

20 Lisboa C, Pare PD, Pertuze J, et al. Inspiratory muscle function in unilateral diaphragmatic paralysis. Am Rev Respir Dis 1986; 134: 488-492.

21 Koo P, Oyieng'o DO, Gartman EJ, et al. The maximal expiratory-to-inspiratory pressure ratio and supine vital capacity as screening tests for diaphragm dysfunction. Lung 2017; 195: 29-35.

22 Miller JM, Moxham J, Green M. The maximal sniff in the assessment of diaphragm function in man. Clin Sci 1985; 69: 91-96.

23 Caleffi Pereira M, Dacha S, Testelmans D, et al. Assessing the effects of inspiratory muscle training in a patient with unilateral diaphragm dysfunction. Breathe 2019: 15: e90-e96.

24 Mills GH, Kyroussis D, Hamnegard CH, et al. Cervical magnetic stimulation of the phrenic nerves in bilateral diaphragm paralysis. Am J Respir Crit Care Med 1997; 155: 1565-1569.

25 Luo YM, Hart N, Mustfa N, et al. Reproducibility of twitch and sniff transdiaphragmatic pressures. Respir Physiol Neurobiol 2002; 132: 301-306.

$26 \mathrm{Xu} \mathrm{Y}$, Rui J, Zhao X, et al. Effect of isolated unilateral diaphragmatic paralysis on ventilation and exercise performance in rats. Respir Physiol Neurobiol 2014; 196: 25-32.

27 Manning HL, Schwartzstein RM. Pathophysiology of dyspnea. N Engl J Med 1995; 333: 1547-1553.

28 Dube BP, Dres M. Diaphragm dysfunction: diagnostic approaches and management strategies. J Clin Med 2016; 5: 113.

29 Chatham K, Gelder CM, Lines TA, et al. Suspected statin-induced respiratory muscle myopathy during long-term inspiratory muscle training in a patient with diaphragmatic paralysis. Phys Ther 2009; 89: 257-266.

30 Kodric M, Trevisan R, Torregiani $\mathrm{C}$, et al. Inspiratory muscle training for diaphragm dysfunction after cardiac surgery. J Thorac Cardiovasc Surg 2013; 145: 819-823.

31 Petrovic M, Lahrmann H, Pohl W, et al. Idiopathic diaphragmatic paralysis--satisfactory improvement of inspiratory muscle function by inspiratory muscle training. Respir Physiol Neurobiol 2009; 165: 266-267. 